\title{
Removal of Arsenic from Waste Water by Using ZnO Nano-Materials
}

\author{
Sanjay Srivastava and Yogesh Srivastav \\ Material Science \& Metallurgical Engineering, Maulana Azad National Institute of Technology, Bhopal M.P. 462051, India
}

Received: July 08, 2011 / Accepted: August 02, 2013 / Published: August 25, 2013.

\begin{abstract}
Zinc oxide has a unique position among semiconducting oxides due to its piezoelectric and transparent conducting properties. The catalyst-free synthesis of pure $\mathrm{ZnO}$ nanostructured material with 6-fold structural symmetry was synthesized by the chemical precipitation method. In this article, various nanostructures of $\mathrm{ZnO}$ which are grown by the chemical precipitation technique has been reported. Zinc oxide nanoparticles were synthesized by heating freshly prepared zinc hydroxide $\left[\mathrm{Zn}(\mathrm{OH})_{2}\right]$ at $150^{\circ} \mathrm{C}$ for two hours. The prepared compound was characterized by the X-Ray diffraction technique. Zinc oxide nanoparticles possess high removal capacity of As (III), which can easily be separated and recycled during water treatment processes.
\end{abstract}

Key words: RAMAN spectra, XRD, heavy metal, PIM, PVA, SEM, PL spectra.

\section{Introduction}

Zinc oxide $(\mathrm{ZnO})$ is a unique material that exhibits Semiconductor as well as piezoelectric properties. It has high electrical conductivity and optical transmittance in the visible region. These properties make it an ideal candidate for applications like transparent conducting electrodes in flat panel displays and window layers of solar cells [1-4]. ZnO has a wide band gap of $3.37 \mathrm{eV}$ and large exciton binding energy $(60 \mathrm{meV})$ that exhibit many potential applications in areas such as laser diodes, solar cells, gas sensors, optoelectronic devices. By proper alloying with $\mathrm{MgO}$ or $\mathrm{CdO}$, the band gap can be tuned in the range of 3-4 eV. $\mathrm{ZnO}$ nanostructures play an active role in nano devices like nano gas sensors, because high surface area enhances the gas sensing properties of the sensors. $\mathrm{ZnO}$ has three crystal forms: the hexagonal wurtzite, cubic zinc Blende and cubic rock salt which is rarely observed. The Wurtzite structure is most commonly used as, it has high stability under normal working conditions. Hexagonal

Corresponding author: Sanjay Srivastava, associte professor, research field: composite materials. E-mail: s.srivastava.msme@gmail.com. and zinc Blende structures do not display inversion symmetry and due to these properties they are responsible for the piezoelectricity and pyroelectricity of $\mathrm{ZnO}$.

Gao et al., [5] have prepared the rotor-like $\mathrm{ZnO}$ nanostructure by a hydrothermal method. The hierarchical $\mathrm{ZnO}$ nanostructures with 6-, 4-, and 2 -fold structural symmetry that has been synthesized on $\mathrm{In}_{2} \mathrm{O}_{3}$ core nanowire by heating the intermixture of $\mathrm{ZnO}, \mathrm{In}_{2} \mathrm{O}_{3}$ and graphite powder at $1,000{ }^{\circ} \mathrm{C}[6]$.

Recently, various techniques have been developed to fabricate $\mathrm{ZnO}$ nanocrystals with different shapes, which include metal-catalyzed vapor-liquid-solid (VLS) growth, physical vapor deposition (PVD), chemical vapor deposition (CVD), metal-organic vapor-phase epitaxy, metal-organic CVD, template-assisted growth and oxidation method [7-9]. During their growth, complicated synthesis procedures or the introduction of impurities is detrimental to the properties of the device. Exploring simple, cheap, catalyst-free and low-temperature methods of synthesizing hierarchical $\mathrm{ZnO}$ nanostructures still remains a challenge. $\mathrm{ZnO}$ is a material that has a diverse range of nanostructures, 
whose configurations are far richer than any other known nanomaterials including carbon nanotubes $[2$, 7, 10, 11]. As a part of these studies, photoluminescence (PL) spectra of $\mathrm{ZnO}$ nanostructures have been widely reported. Excitonic emission has been observed from the PL spectra of $\mathrm{ZnO}$ nanorods. Quantum confinement was also observed to be responsible in causing a blue shift in the near UV emission peak in the $\mathrm{ZnO}$ nanobelts. Some other fields of application include optical fibers, surface acoustic wave devices, solar cells, etc. [3, 7]. $\mathrm{ZnO}$ has a wide direct band gap $(3.37 \mathrm{eV})$ and a relative large excitation binding energy $(60 \mathrm{meV})$. Owing to its unique properties of wide band gap and large excitation binding energy, $\mathrm{ZnO}$ has the potential to be applied in chemical sensors, solar cells, luminescence devices etc. $\mathrm{ZnO}$ nanowires are also reported to behave like n-type semiconductor due to the presence of interstitial defects and vacancies [3, 10-12]. The major roadblock of $\mathrm{ZnO}$ for widespread applications in electronics and Photonics is its problems with p-type doping.

In this paper, we demonstrate a simple chemical precipitation route for the synthesis of $\mathrm{ZnO}$ nanostructure materials. The Zinc oxide nanostructure material was synthesized from zinc hydroxide. SEM and XRD analysis were carried out for the determination of surface feature and phase analysis. The UV-visible spectra of $\mathrm{ZnO}$ nanostructure materials were recorded with the help of spectrophotometer in the wavelength region of 200-800 nm.

Arsenic is one of the major pollutants in ground water and responsible for a number of diseases related to lungs, bladder and skin cancer. The toxicity of arsenic varies greatly according to its oxidation state. As(III) have been reported to be more toxic than $\mathrm{As}(\mathrm{V})$. This can be removed by chemical and physical methods. In this article, we use $\mathrm{ZnO}$ nanostructure materials for removing the As(III) from the wastewater.

\section{Experiments}

\subsection{Material Synthesis}

Zinc oxide was prepared from Zinc hydroxide solution after neutralizing with $\mathrm{NaOH}$. Conventional heating experiments were conducted on magnetic stirrer for the experiment. On the completion of the reaction, the solid and solution phases were separated by centrifugation and the solids were washed free of salts with de-ionized water thrice followed by ethanol twice. A white colored powder was calcined at $150{ }^{\circ} \mathrm{C}$ and then it was ground for uniformities of the powder. The dry synthetic powders were weighed and the percentage yield was calculated from the expected total amount of $\mathrm{ZnO}$ based on the solution concentration and volume and the amount that was actually crystallized.

\subsection{Characterization}

Powder X-Ray diffraction of prepared nanosized $\mathrm{ZnO}$ was recorded with the help of Rigaku X-ray diffractometer between $10^{\circ}$ to $60^{\circ}$ using $\mathrm{CuK} \alpha$ radiation (1.5414 $\AA$ ). The UV-Visible spectra of all the solutions were recorded with the help of using Jasco V 500 spectrophotometer in the wavelength region of 200-800 $\mathrm{nm}$. The metallographic specimens were prepared using standard technique and studied under SEM for observing the different feature present in the nanostructure materials.

\subsection{Arsenic Removal Experiments}

A solution made by diluting As(III) standard solution $(0.01 \mathrm{M}, 0.03 \mathrm{M}, 0.05 \mathrm{M}$ concentration solutions of arsenic oxide $\left(\mathrm{As}_{2} \mathrm{O}_{3}\right)$, Sigma-Aldrich) in deionized water was used as a source of $\mathrm{As}(\mathrm{III})$. The acidity of the solution was maintained by using nitric acid. Different concentrations of As(III) solution were prepared at a $\mathrm{pH}$ of 4.0. $\mathrm{ZnO}$ nanostructure materials were used to remove the As(III) from the water solution. For each sample, $0.02 \mathrm{~g}$ of synthesized $\mathrm{ZnO}$ powder was added to $20 \mathrm{~mL}$ of As(III) solution. Batch 
adsorption kinetic experiments were carried out by agitating at a speed of $400 \mathrm{rpm} 0.02 \mathrm{~g}$ of adsorbent with a $1 \mathrm{~L}$ aqueous solution of $\mathrm{As}(\mathrm{III})$ at a concentration of $0.01 \mathrm{M}$ in glass flasks placed in a temperature controlled water bath at a constant temperature of $20{ }^{\circ} \mathrm{C}$. The schematic diagram of the experimental apparatus is shown in Fig. 1. The mixture was agitated for $1 \mathrm{~h}$ and then placed for $5 \mathrm{~h}$ to establish equilibrium at room temperature. The $\mathrm{ZnO}$ powder was then separated from the mixture by centrifugation technique. To determine the amount of As(III) removed by the $\mathrm{ZnO}$ powder, $\mathrm{As}(\mathrm{III})$ concentration was measured before and after establishing the equilibrium using Jasco V 500 spectrophotometer in the wavelength region of 200-800 nm. The absorption isotherm was obtained by varying the initial As(III) concentration. The amount of As(III) adsorbed, $q_{\mathrm{e}}\left(\mathrm{mg} \mathrm{g}^{-1}\right)$, was obtained as follows:

$$
q=\frac{\left(C_{0}-C_{e}\right) V}{W}
$$

Where $C_{0}$ and $C_{\mathrm{e}}$ are the initial and equilibrium liquid-phase concentrations of $\mathrm{As}(\mathrm{III})\left(\mathrm{mg} \cdot \mathrm{L}^{-1}\right)$, respectively, $V$ is the volume of solution (L) and $W$ is the amount of adsorbent used (g).

\section{Results and Discussion}

The synthesis of nanostructures is a growing area of research. The synthesis of nanostructures by low cost process would be of great technological importance. The $\mathrm{ZnO}$ nanostructures were synthesized by co-precipitation methods. In this research work, the $\mathrm{ZnO}$ nanoparticles were prepared from zinc hydroxide. Based on a fixed proportion, the nanoparticles place inside the deionized water for $72 \mathrm{~h}, 168 \mathrm{~h}$, and $336 \mathrm{~h}$ respectively, so as to observe the oxidation and precipitation status of the nanoparticles. In order to verify the result obtained from the precipitation that the nature of the nanoparticles inside the deionized water will change according to time. Fig. $2 \mathrm{a}$ is the SEM image of $\mathrm{ZnO}$ nanofluid after placement of
$168 \mathrm{~h}$. The morphology of $\mathrm{ZnO}$ that was synthesized from co-precipitation methods was investigated by using a SEM. As it can be seen that the particles display rod-like form, which indicates the growth of the nanostructures along a certain direction. Its axial length is around $250 \mathrm{~nm}$. It can be clearly seen that the nanoparticles do not have a fixed shape and their distribution is not obvious, but in turn, they become oxidized material clustering and growing irregularly as shown in Fig. 2 b.

The XRD patterns of the zinc oxide powders were examined, and are given in Fig. 3. The Miller indices of the reflective crystal planes and d-spacing's between them are indicated on the XRD patterns. The strongest characteristic $101 \mathrm{XRD}$ reflection of the $\mathrm{Zn}(\mathrm{OH})_{2}$ crystal in the precursor powder is at 0.7357 nm. Zinc oxide crystal has several XRD reflections. Its characteristic XRD reflections at 0.2807, 0.2596, and $0.2470 \mathrm{~nm}$ correspond to 100,002 , and 101 planes, respectively.

These reflections match with the Wurtzite structural $\mathrm{ZnO}$ with lattice constants of $\mathrm{a}=0.3250 \mathrm{~nm}$ and $\mathrm{c}=$ $0.5207 \mathrm{~nm}[13,14]$. This structure does not depend on the preparation processes and the morphology of the $\mathrm{ZnO}$ powders [15-17]. It is known that the decrease in width of an XRD peak shows the increase in size of the investigated crystal. The relationship between the average crystal size (L) and FWHM in terms of radians is given as follows by the Scherrer formula:

$$
L=\frac{0.9 \lambda}{(F W H M) \cos \theta}
$$

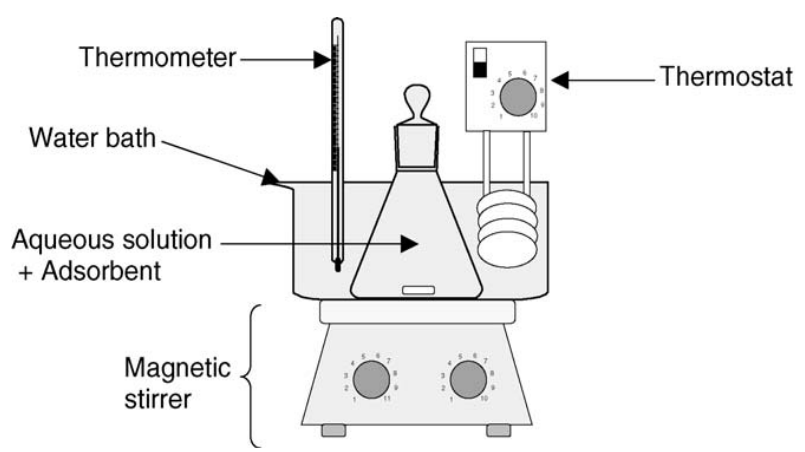

Fig. 1 Experimental apparatus used for adsorption kinetic studies. 

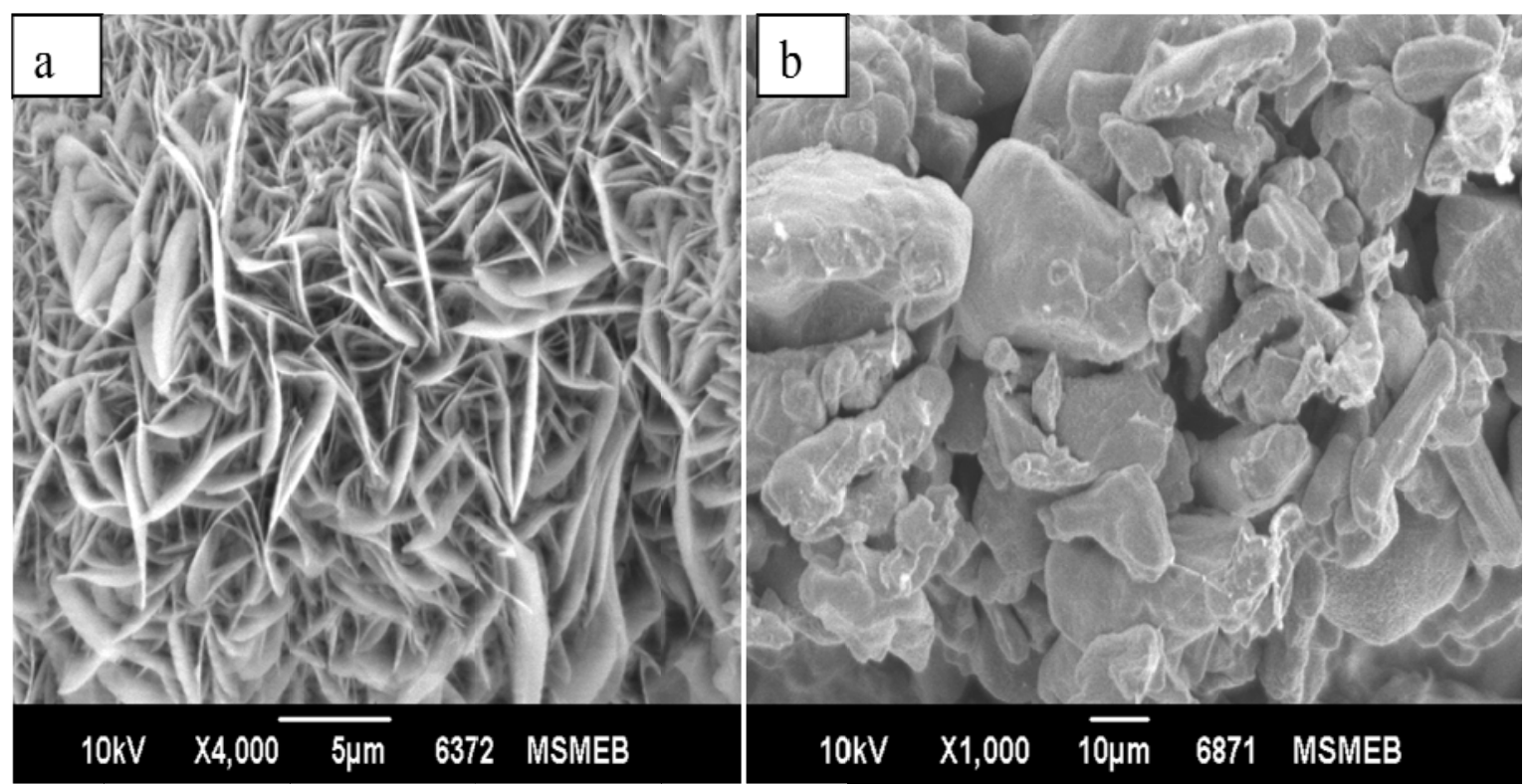

Fig. 2 SEM image of $\mathrm{ZnO}$ nanoparticle that is placed in deionized water for $168 \mathrm{~h}$,

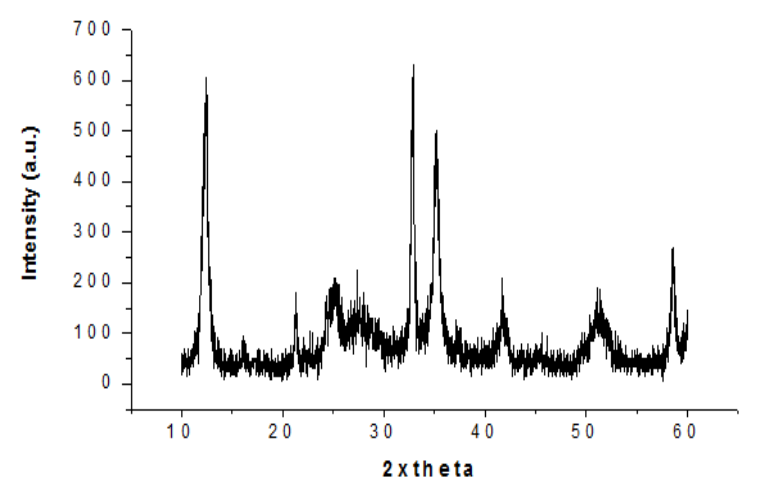

Fig. 3 Typical XRD pattern of the zinc oxide.

where, $\lambda$ is the wavelength of the X-rays, FWHM is the full width at half maximum reflection height, and $\theta$ is the diffraction angle. The average size of particles in oxide powders was found to be $32 \mathrm{~nm}$ by using the data for the most characteristic $101 \mathrm{XRD}$ reflections.

Fig. 4 shows the Raman spectra of $\mathrm{ZnO}$ nanoparticles prepared from co-precipitation technique. Raman measurements were also made using $785 \mathrm{~nm}$ line of solid state laser; however, the existence of large PL background prevented a quantitative analysis of Raman intensities. The Raman spectra shows the main vibrational bands at 901, 58, $606.5,481.33,399.33$ and $239.25 \mathrm{~cm}^{-1}$. Wurtzite type $\mathrm{ZnO}$ belongs to the $\mathrm{C}_{6 \mathrm{v}}(\mathrm{P} 63 \mathrm{mc})$ space symmetry. Each unit cell is having 4 atoms and occupying $2 \mathrm{~b}$ sites of symmetry $\mathrm{C}_{3 \mathrm{v}}$. At the point near the Brillouin zone the following optical phonon modes are allowed, $\Pi_{\mathrm{opt}}=\mathrm{A} 1+2 \mathrm{~B} 1+\mathrm{E} 1+2 \mathrm{E} 2$. Among these, doubly degenerate $\mathrm{B} 1$ modes are silent, $\mathrm{A} 1$ and $\mathrm{E} 1$ branches are both Raman and infrared active, and other doubly degenerate E2 modes are Raman active.

Fig. 5 shows the optical absorption of $\mathrm{ZnO}$ nanoparticles. The absorption spectra demonstrates the absorption peaks around $386 \mathrm{~nm}(3.23 \mathrm{eV})$ corresponding to the exciton state in the bulk $\mathrm{ZnO}$. Even though these spectra were taken at room temperature, the $\mathrm{ZnO}$ nanoparticle samples exhibit salient exciton absorption features due to the relatively large binding energy of the exciton $(60 \mathrm{mV})$.

Fig. 6 depicts the photoluminescence spectrum of nanosized $\mathrm{ZnO}$ synthesized in aqueous medium. Strong emission peak centered at $397 \mathrm{~nm}$ was observed in $\mathrm{ZnO}$. The $\mathrm{ZnO}$ sample exhibits only UV band gap luminescence but no oxygen defect luminescence was observed. The nano powders show an intense violet emission along with the emission in a blue and green band. The average position of the most intense peak lies in the violet band in the range 417-424 nm. Blue emission band occurs in the range (a) 447-455 nm (Band-I) (b) 485-486 nm (Band-II). 
Generally, a green-yellow emission, it is observed around $530 \mathrm{~nm}$, i.e., green-yellow emission as shown in Fig. 6. In the photoluminescence (PL) spectra of $\mathrm{ZnO}$, typically there are emission bands in the UV and visible regions. The UV peak is usually considered as the characteristic emission of $\mathrm{ZnO}$ and attributed to the band edge emission or the exciton transition.

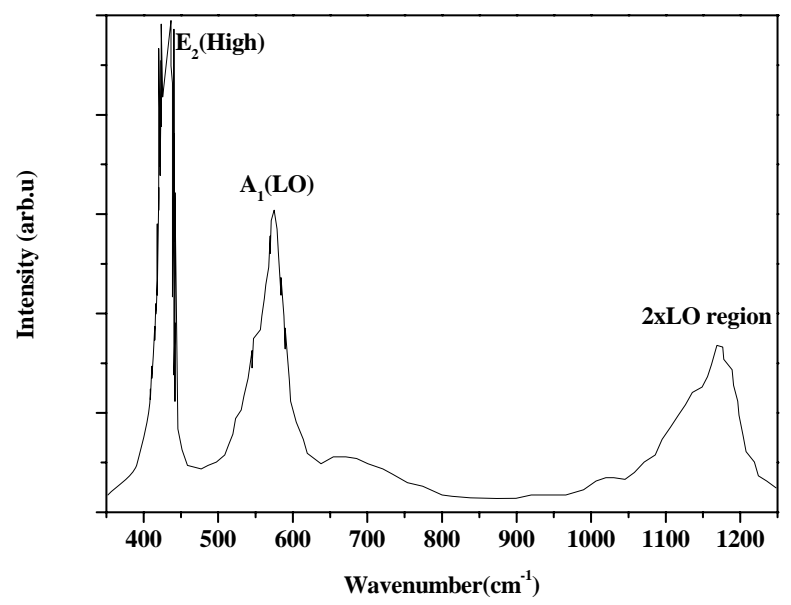

Fig. 4 Raman spectra of $\mathrm{ZnO}$ nanoparticles.

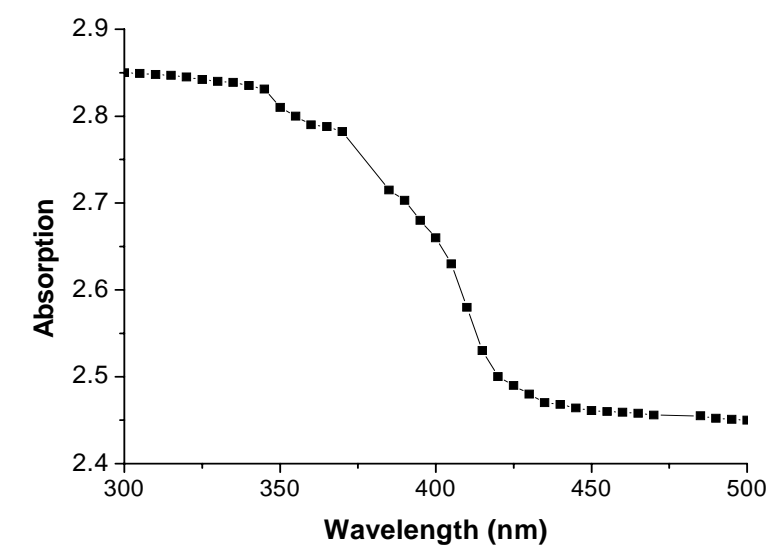

Fig. 5 UV absorption spectrum of ZnO sample.

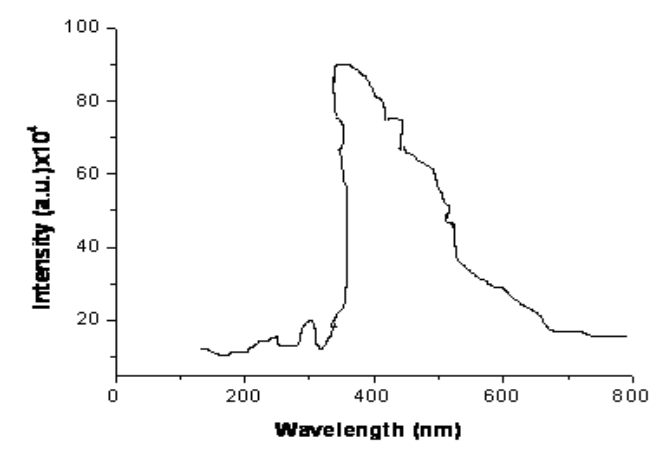

Fig. 6 PL spectrum of obtaining sample.

\subsection{Arsenic Removal}

Arsenic has been identified as a major contamination source of ground water/waste water. The toxicity of As varied greatly to the oxidation state. As (III) is a highly poisonous form out of the present contaminated parts in ground water. As (III) has been reported to be more toxic than As (V) and methylated arsenic compounds. The adsorption isotherm of As (III) on $\mathrm{ZnO}$ nanostructure materials is shown in Fig. 6. The obtained results show a better adsorption of As (III) on $\mathrm{ZnO}$ nanostructure materials. Isotherms show the shape of type $\mathrm{L}$ according to the classification of Giles et al. [18]. The L or Langmuir shape of the isotherms means that there is no strong competition between the solvent and the adsorbate to occupy the adsorbent sites. In this case, the longitudinal axes of the adsorbed molecules are parallel to the adsorbent surface [18]. Adsorption isotherms are important for the description of how adsorbates will interact with an adsorbent and are critical in optimizing the use of adsorbent. The Langmuir model is given by the following relation:

$$
\frac{q_{e}}{q_{m}}=\frac{b C_{e}}{1+b C_{e}}
$$

where, $C e$ is the liquid-phase concentration of the adsorbate at equilibrium $\left(\mathrm{mg} \cdot \mathrm{L}^{-1}\right), q_{\mathrm{e}}$ is the amount of adsorbate adsorbed at equilibrium $\left(\mathrm{mg} \cdot \mathrm{g}^{-1}\right), q_{\mathrm{m}}$ is the maximum adsorption capacity $\left(\mathrm{mg} \cdot \mathrm{g}^{-1}\right)$ and $b$ is the Langmuir constant related to the energy of adsorption $\left(\mathrm{L} \cdot \mathrm{mg}^{-1}\right)$.

According to Stumm and Morgan representation (Form I):

$$
\frac{1}{q_{e}}=\frac{1}{q_{m}}+\frac{1}{q_{m} b C_{e}}
$$

According to the representation of Weber [20] (Form II):

$$
\frac{C_{e}}{q_{e}}=\frac{1}{b q_{m}}+\frac{C_{e}}{q_{m}}
$$

If the adsorption obeys Langmuir equation, maximum adsorption capacity and Langmuir constant can be evaluated from the slopes and the intercepts of 
the plots $C_{e} / q_{e}$ versus $C_{e}$ (form II) or $1 / q_{e}$ versus $1 / C_{e}$ (Form I).

The modeling of experimental results of the adsorption isotherms by the Langmuir equation (Fig. 7) presents considerable differences according to the mode of exploitation (linearization). It appears that the method of linearization thus intervenes in the estimation of the adsorption isotherms parameters.

The favorable nature of adsorption can be expressed in terms of dimensionless separation factors of equilibrium parameter, which is defined by the equation [21]:

$$
R_{L}=\frac{1}{1+b C_{o}}
$$

where, $b$ is the Langmuir constant and $C_{0}$ is the initial concentration of the adsorbate in solution. The values of $R_{\mathrm{L}}$ indicate the type of isotherm to be irreversible $\left(R_{\mathrm{L}}=0\right)$, favorable $\left(0<R_{L}<1\right)$, linear $\left(R_{L}=1\right)$ or unfavorable $\left(R_{L}>1\right)$. $R L$ values for As (III) adsorption onto $\mathrm{ZnO}$ nanoparticles were less than 1 and greater than zero indicating favorable adsorption. The Freundlich equation may be written as

$$
q_{e}=k_{F} C_{e}^{1 / n}
$$

$K_{\mathrm{F}}$ is a constant indicative of the adsorption capacity of the adsorbent $\left(\mathrm{mg}^{1-(1 / n)} \cdot \mathrm{L}^{1 / n} \cdot \mathrm{g}^{-1}\right)$ and $n$ is an empirical constant related to the magnitude of the adsorption driving force. According to Halsey [22]:

$$
k_{F}=\frac{q_{m}}{C_{e}^{1 / n}}
$$

To determine the maximum adsorption capacity, it is necessary to operate with constant initial concentration $C_{0}$ and variable weights of adsorbent; thus, $\ln q_{\mathrm{m}}$ is the extrapolated value of $\ln q$ for $\mathrm{C}=C_{0}$. If the adsorption obeys Freundlich equation, $K_{\mathrm{F}}$ and $n$ can be obtained from the plot of $\ln q_{\mathrm{e}}$ versus $\ln C_{\mathrm{e}}$. The Freundlich isotherms for the adsorption of As (III) on $\mathrm{ZnO}$ nanostructure materials are presented in Fig. 8. The values of maximum adsorption capacity, determined from Freundlich model, are much higher than experimental values. The correlation coefficients showed that the Langmuir model (form II) fitted the results better than the Freundlich model. The Langmuir model makes several assumptions, such as monolayer coverage and constant adsorption energy while the Freundlich equation deals with heterogeneous surface adsorption. The applicability of both Langmuir and Freundlich isotherms to both Sorbent systems implies that both monolayer adsorption and heterogeneous surface conditions exist under the used experimental conditions.

\subsection{Adsorption Kinetics}

The adsorption of a solute by a nano structure solid in aqueous solution is a phenomenon whose kinetics is often complex. The adsorption rate of $\mathrm{As}(\mathrm{III})$ on $\mathrm{ZnO}$ nanostructure materials is strongly influenced by several parameters related to the state of the solid, generally having very heterogeneous reactive surface area and the physicochemical conditions under which adsorption is carried out.

The adsorption data for the adsorption rate of As (III) on $\mathrm{ZnO}$ nanostructure materials versus contact time are presented in Fig. 9. Differences between the adsorption rates seems to be more marked at the beginning of adsorption; the observed variation decreases with time. Initially the maximum amount of $\mathrm{As}(\mathrm{III})$ absorbed on the surface. In general, adsorption may be described as a transport of the adsorbate from

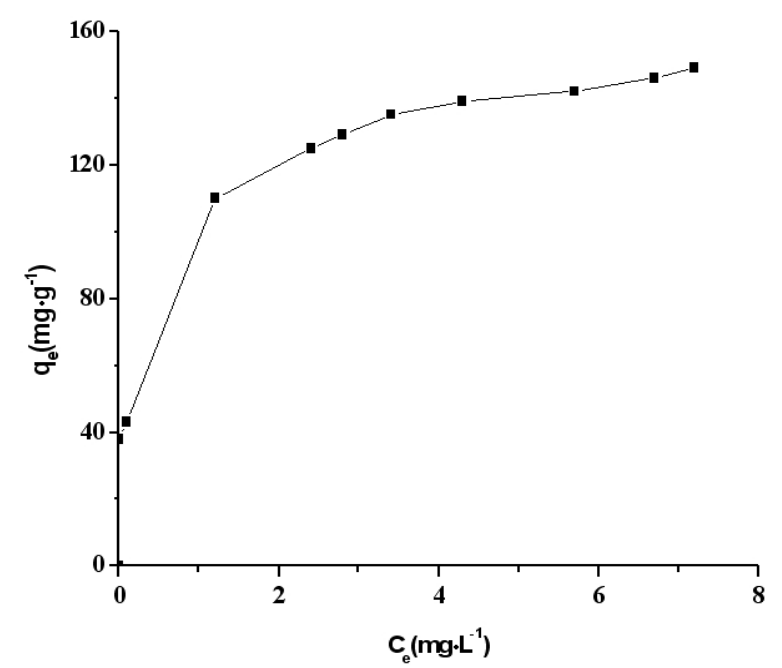

Fig. 7 Absorption isotherm of As (III) on the as-prepared $\mathrm{ZnO}$ sample with hair like structure at $25^{\circ} \mathrm{C}$. 


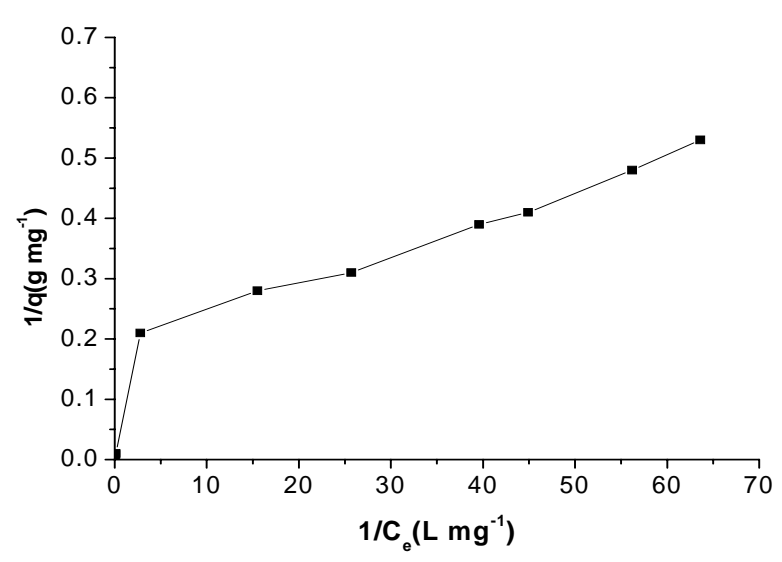

Fig. 8 Langmuir plots of As (III) adsorption by $\mathrm{ZnO}$ nanostructure materials.

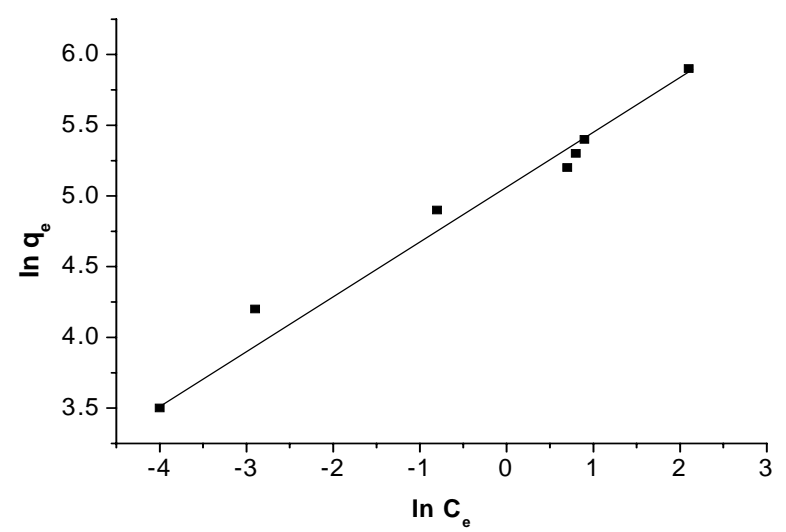

Fig. 9 Freundlich plot for As(III) adsorption onto $\mathrm{ZnO}$ nanostructure materials.

the fluid to the external surface of the adsorbent across the boundary layer (film diffusion), and diffusion of the adsorbate within the pores of the adsorbent (particle diffusion). If the process is controlled by the external resistance, the plot $\ln C$ versus time must be linear [23]. This kind of relation is shown for the first stage adsorption kinetics of $\mathrm{As}(\mathrm{III})$ onto $\mathrm{ZnO}$ nanostructure materials. It seems that the external diffusion is the rate-controlling step of the initial fast adsorption of $\mathrm{As}(\mathrm{III})$ on $\mathrm{ZnO}$ nanostructure materials.

\subsection{Surface Investigation of $\mathrm{ZnO}$ Nanostructure} Materials by the Absorption of As(III)

The synthesis of nanostructures by a low cost process would be of great technological importance. The $\mathrm{ZnO}$ nanostructures were synthesized by co-precipitation technique. The SEM observation shows needle like structures of $\mathrm{ZnO}$ formed from co-precipitation technique. The environmental fate of Arsenic in environments is highly dependent on the Arsenic speciation. Ionic strength, $\mathrm{pH}$, and the presence of adsorbents such as nanostructure materials, metal oxides and phyllosilicates. In this experiment, As(III) was absorbed on the $\mathrm{ZnO}$ nanostructure materials. The morphology of the As(III) absorbed on the $\mathrm{ZnO}$ nanostructure was investigated from SEM observation. Fig. 9 shows the SEM micrograph of As(III) absorbed on the $\mathrm{ZnO}$ nanostructure materials. In aqueous state, the morphology of the $\mathrm{ZnO}$ nanostructure has not been changed during As(III) absorption on this surface. The axial length of the $\mathrm{ZnO}$ nanostructure materials after As(III) absorption was also investigated from SEM observation. From the SEM investigation, the axial length of the $\mathrm{ZnO}$ nanostructure materials after $\mathrm{As}$ (III) absorption is roughly $2.07 \mu \mathrm{m}$ and the diameter of the $\mathrm{ZnO}$ nanostructure materials after As(III) absorption becomes $240 \mathrm{~nm}$ as shown in Fig. 9b. A $\mathrm{ZnO}$ nanostructure material is amphoteric in nature. It is dissolved either in acid or in alkaline solution. Therefore, the absorption experiment was commenced in a neutral environment. In acid to alkaline environments, arsenic can be adsorbed onto variable-charge absorbed surfaces by inner-sphere and/or outer-sphere complexation. Inner-sphere

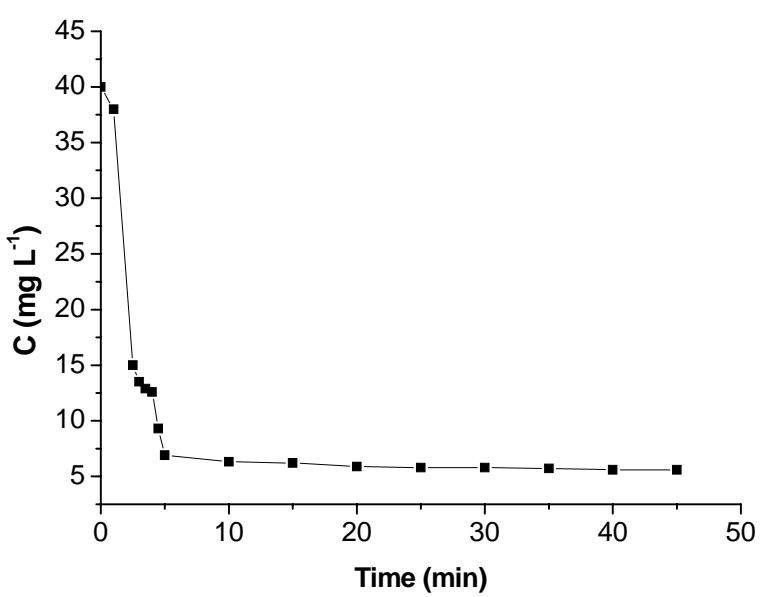

Fig. 10 Dynamics of As (III) adsorption onto As (III) for ZnO nanostructure materials. 

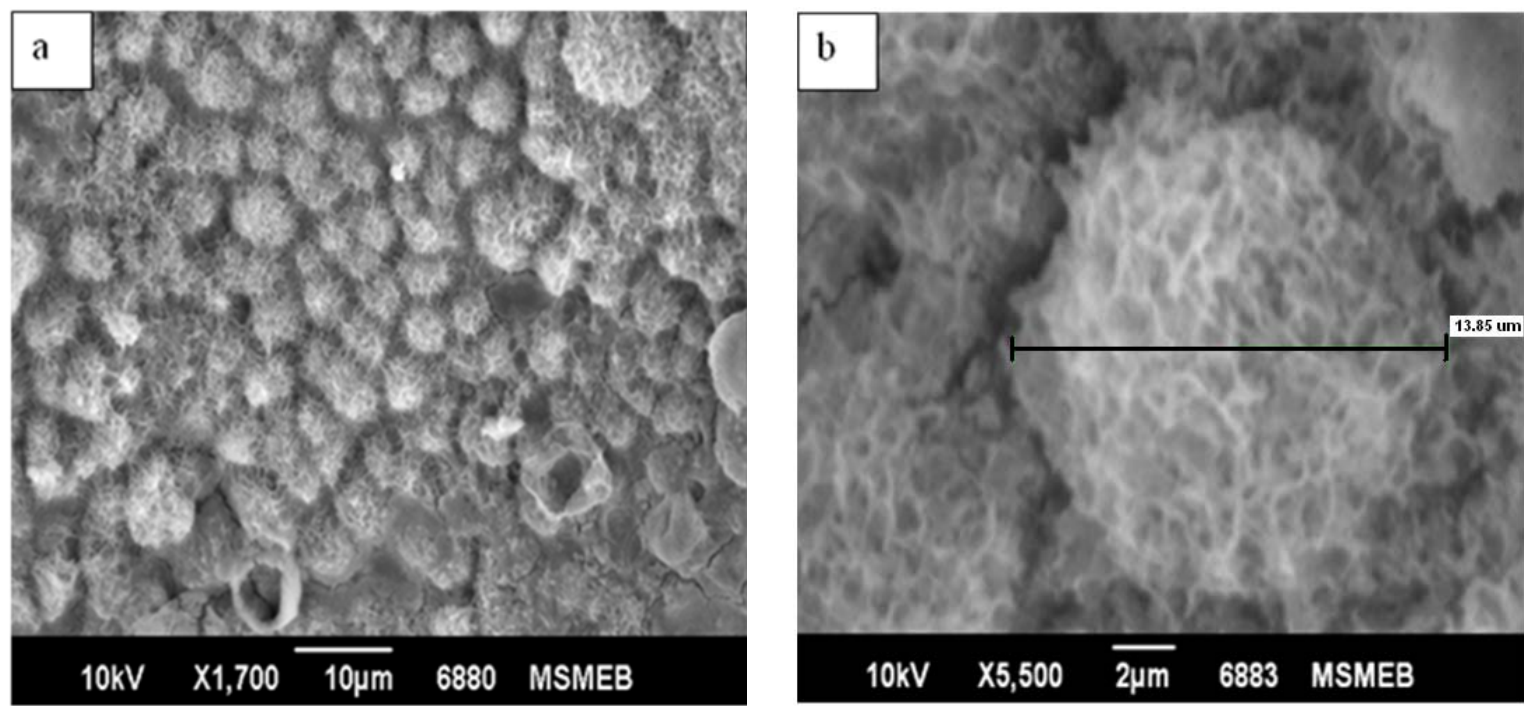

Fig. 11 SEM observation of As(III) absorbed on the ZnO nanostructured materials.

complexes form via a ligand exchange reaction with a surface functional group, and as a result, no water molecules are present between surface functional groups and the adsorbate ions. Outer-sphere complexes from mainly by electrostatic interactions and contain more than one water molecule between the adsorbate and the adsorbent functional groups. XRD analysis was carried out to investigate surface feature of $\mathrm{ZnO}$ after the absorption of As (III) from the waste water solution. Fig. 12 shows the XRD micrograph of $\mathrm{ZnO}$ modified by the absorption of As (III) on the surface. The peak position of As (III) was found at $2 \theta=14.53$ and 27.38 along with $\mathrm{ZnO}$ peak. Due to absorption of

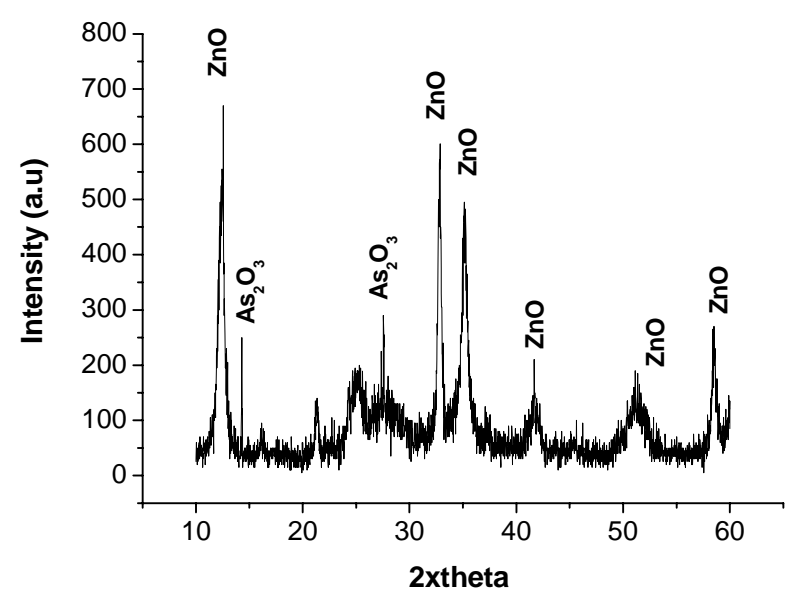

Fig. 12 Typical XRD pattern of the zinc oxide.

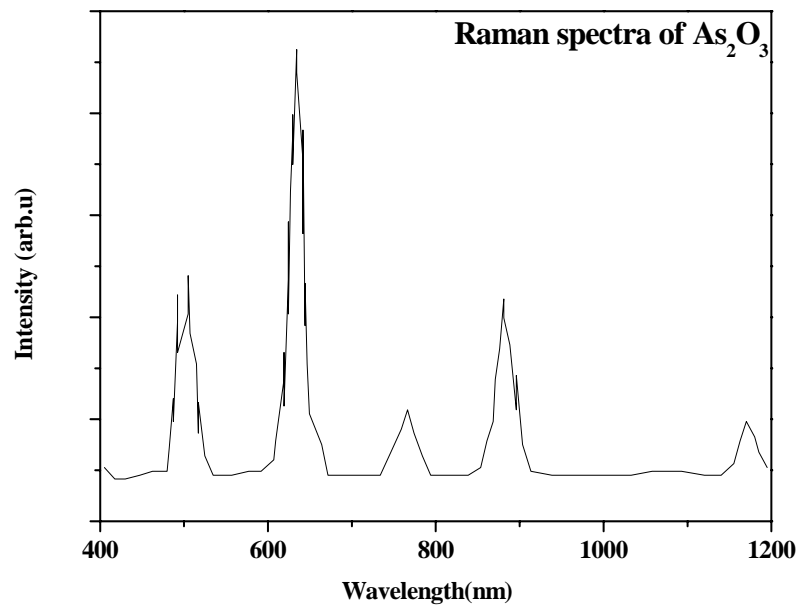

(a)

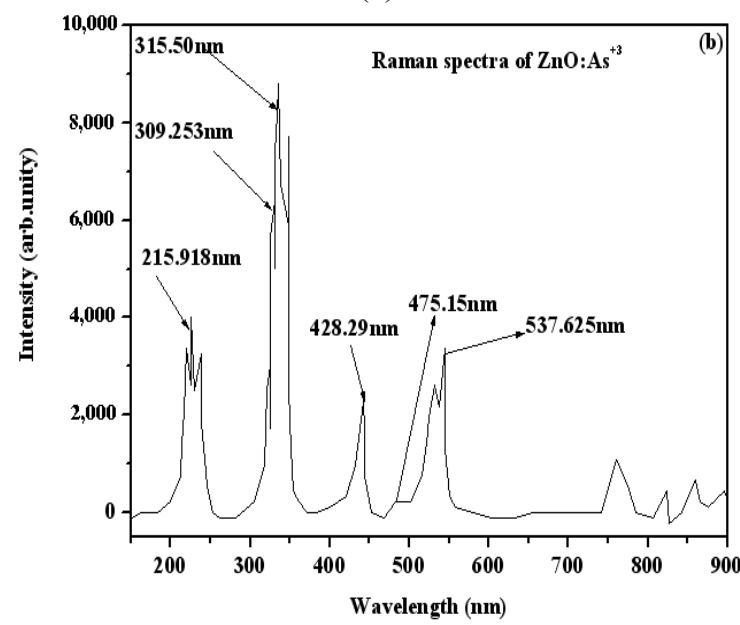

(b)

Fig. 13 Raman spectra of (a) $\mathrm{As}_{2} \mathrm{O}_{3}$ and (b) $\mathrm{As}_{2} \mathrm{O}_{3} \mathrm{ZnO}$ nanoparticles. 
The surface absorption was also investigated from As (III), the peak intensity of the $\mathrm{ZnO}$ nanostructure has been reduced.

Raman spectroscopy. And their results are shown in Fig. 13a and 13b. Raman spectra of pure As (III) oxide is shown in Fig. 13a and Raman spectra of the absorbed surface are shown in Fig. 13b. The Raman shifts in As (III) are found at 309.253, 15.509, 215.918, 418, 475.151, 520.625, 562.692, and 782.261. From the peak observation it was found that the As (III) from the waste water has been absorbed on the $\mathrm{ZnO}$ nano structure materials.

\section{Conclusions}

The results of present investigation show that Zinc oxide nanoparticles, have suitable adsorption capacity with regard to the removal of arsenic from its aqueous solution. The $\mathrm{ZnO}$ nano particles were synthesized from co-precipitation methods. The estimated size of the $\mathrm{ZnO}$ nano particles is approximately $32 \mathrm{~nm}$. The data obtained from the experimental results are applied to the Langmuir, and Freundlich, isotherm to test the fitness of these equations. By considering the experimental results and adsorption models applied in this study of the arsenic removal, it can be concluded that adsorption of arsenic obeys Langmuir isotherm, and Freundlich isotherms model. Freundlich isotherms model is less suitable than that of Langmuir.

Adsorption kinetics follows pseudo-second order kinetic model. Kinetic results showed that both filmand particle diffusion are effective adsorption mechanisms. The adsorption is a two-stage process comprising a fast initial phase and a slower second phase. In the first phase, arsenic (III) is adsorbed at the outer sites of the $\mathrm{ZnO}$ nanoparticles due to high surface area. In the second phase, arsenic (III) from the aqueous solution slowly diffuses inward and adsorb to the inner sites of the $\mathrm{ZnO}$-adsorbents. The absorption of the arsenic on the surface was investigated by the SEM, XRD and Raman spectroscopy. They produce the reproducible results.

\section{References}

[1] Z.L. Wang, Zinc oxide nanostructures: Growth, properties and applications, Journal of Physics: Condensed Matter 16 (2004) R829-R858.

[2] Z.Y. Fan, G.J. Lu, Zinc Oxide nanostructures: Synthesis and properties, Journal of Nanoscience and Nanotechnology 5 (2005) (10) 1561-1573.

[3] S. Baruah, J Dutta, Hydrothermal growth of $\mathrm{ZnO}$ nanostructures, Sci. Technol. Adv. Mater. 10 (2009).

[4] A. Hernandezbattez, R. Gonzalez, J. Viesca, J. Fernandez; J. Diazfernandez, A. MacHado, et al., $\mathrm{CuO}, \mathrm{ZrO}_{2}$ and $\mathrm{ZnO}$ nanoparticles as antiwear additive in oil lubricants, Wear 265 (3-4) (2008) 422-428.

[5] P.X. Gao, Z.L. Wang, Nanopropeller arrays of zinc oxide, Appl. Phys. Lett. 84 (2004) (15) 2883.

[6] J.Y. Lao, J.G. Wen, Z.F. Ren, Hierarchical ZnO nanostructures, Nano. Lett. 2 (2002) 1287.

[7] Z. Chen., Z. Shan, S. Li, C.B. Liang, S.X. Mao, A novel and simple growth route towards ultra-fine $\mathrm{ZnO}$ nanowires, J. Cryst. Growth 265 (2004) 482-486.

[8] A. Sekar, S.H. Kim, A. Umar, Y.B. Hahn, Catalyst-free synthesis of $\mathrm{ZnO}$ nanowires on $\mathrm{Si}$ by oxidation of $\mathrm{Zn}$ powders, J. Cryst. Growth 277 (2005) 471-478.

[9] J. Zhang, Y. Yang, B. Xu, F. Jiang, J. Li, Shape-controlled synthesis of $\mathrm{ZnO}$ nano and micro-structures, J. Cryst. Growth 280 (2005) 509-515.

[10] F. Porter, Zinc Handbook: Properties, Processing, and Use in Design, CRC Press, Dekker Mechanical Engineering Series 73 (1991) ISBN 0824783409, 9780824783402

[11] T.K. Subramanyam, B.S. Naidu, S. Uthanna, Physical properties of zinc oxide films prepared by DC reactive magnetron sputtering at different sputtering pressures, Cryst. Res. Technol. 35 (2000) (10) 1194-1202.

[12] W.Z Lin, Zinc oxide nanostructures: Growth, properties and applications, J. Phys.: Condens. Matter. 16 (2004) R829-R858.

[13] C.X. Xu, X.W. Sun, Z.L. Dong, M.B. Yu, Zinc oxide nanodisc, Appl. Phys. Lett. 85 (2004) 3878-3880.

[14] L.W. Yang, X.L. Wu, Y. Xiong, Y.M. Yang, G.S. Huang, P.K. Chu, et al., Formation of zinc oxide micro-disks via layer-by-layer growth and growth mechanism of $\mathrm{ZnO}$ nanostructures, J. Cryst. Growth 283 (2005) 332-338.

[15] X. Feng, Z. Li, P. Wang, Y. Zhou, Preparation and gas-sensitivity of ultra-fine zinc-oxide powders from roasted zinc-blended , J. Sci. 40 (2005) 6597-6600. 
[16] J. Lu, Q. Zhang, J. Wang, F. Saito, M. Uchida, Synthesis of $\mathrm{N}$-Doped $\mathrm{ZnO}$ by grinding and subsequent heating ZnO-urea mixture, Powder Technol. 162 (2006) 33-37.

[17] C.H. Lu, C.H. Yeh, Emulsion precipitation of submicron zinc oxide powder, Mater. Lett. 33 (1997) 129-132.

[18] C.H. Giles, T.H. MacEwan, S.N. Nakhwa, D. Smith, Studies in adsorption: Part 11. A system of classification of solution adsorption isotherms, and its use in diagnosis of adsorption mechanisms and in measurements of specific surface areas of solids, J. Chem. Soc. 10 (1960) 3973-3993.

[19] W. Stumm, J.J. Morgan, Aquatic Chemistry, 2ed., Wiley Interscience, John Wiley \& Sons, 1996 Available as an online resource via the NC State University Library web site (http://www.lib.ncsu.edu/).

[20] J. Weber, Adsorption in Physicochemical Processes for water Quality Control, Wiley Interscience, N.Y., 1972, pp. 199-259 (Chapter 5).

[21] K.R. Hall, L.C. Eagleton, A. Acrivos, T. Vermeulen, Pore and solid diffusion kinetics in fixed bed adsorption under constant pattern conditions, Ind. Eng. Chem. Fundam. 5 (1966) 212-223.

[22] G.D. Halsey, The role of surface heterogeneity, Adv. Catal. 4 (1952) 259-269.

[23] D.M. Nevskaia, A. Santianes, V. Munoz, A. Guerrero-Ruiz, Interaction of aqueous solutions of phenol with commercial activated carbons: An adsorption and kinetic study, Carbon 37 (1999) 1065-1074. 